\title{
Predicting factors for malaria re-introduction: an applied model in an elimination setting to prevent malaria outbreaks
}

\author{
Mansour Ranjbar ${ }^{1,7^{*}}$, Alireza Shoghli ${ }^{2}$, Goodarz Kolifarhood ${ }^{3}$, Seyed Mehdi Tabatabaei ${ }^{4}$, Morteza Amlashi $^{5}$
} and Mahdi Mohammadi ${ }^{6}$

\begin{abstract}
Background: Malaria re-introduction is a challenge in elimination settings. To prevent re-introduction, receptivity, vulnerability, and health system capacity of foci should be monitored using appropriate tools. This study aimed to design an applicable model to monitor predicting factors of re-introduction of malaria in highly prone areas.

Methods: This exploratory, descriptive study was conducted in a pre-elimination setting with a high-risk of malaria transmission re-introduction. By using nominal group technique and literature review, a list of predicting indicators for malaria re-introduction and outbreak was defined. Accordingly, a checklist was developed and completed in the field for foci affected by re-introduction and for cleared-up foci as a control group, for a period of 12 weeks before re-introduction and for the same period in the previous year. Using field data and analytic hierarchical process (AHP), each variable and its sub-categories were weighted, and by calculating geometric means for each sub-category, score of corresponding cells of interaction matrices, lower and upper threshold of different risks strata, including low and mild risk of re-introduction and moderate and high risk of malaria outbreaks, were determined. The developed predictive model was calibrated through resampling with different sets of explanatory variables using R software. Sensitivity and specificity of the model were calculated based on new samples.
\end{abstract}

Results: Twenty explanatory predictive variables of malaria re-introduction were identified and a predictive model was developed. Unpermitted immigrants from endemic neighbouring countries were determined as a pivotal factor (AHP score: 0.181 ). Moreover, quality of population movement (0.114), following malaria transmission season (0.088), average daily minimum temperature in the previous 8 weeks (0.062), an outdoor resting shelter for vectors $(0.045)$, and rainfall (0.042) were determined. Positive and negative predictive values of the model were 81.8 and $100 \%$, respectively.

Conclusions: This study introduced a new, simple, yet reliable model to forecast malaria re-introduction and outbreaks eight weeks in advance in pre-elimination and elimination settings. The model incorporates comprehensive deterministic factors that can easily be measured in the field, thereby facilitating preventive measures.

Keywords: Malaria, Re-introduction, Elimination, Outbreak, Forecast, MEWS, Transmission, Meteorological, Population movement

\footnotetext{
*Correspondence: Mansourrk@gmail.com

${ }^{7}$ Present Address: Independent Malaria Consultant, Member

of Surveillance, Monitoring and Evaluation Technical Expert Group, Global

Malaria Programme, WHO, Geneva, Switzerland

Full list of author information is available at the end of the article
} 


\section{Background}

In the period 2000-2013, substantial reduction of malaria mortality and morbidity in the world was achieved that resulted in the acceleration of efforts towards malaria elimination [1]. In the Global Technical Strategy for Malaria (2016-2030), the vision of a world free of malaria has been highlighted and at least 35 countries with the continuous transmission in 2015 aim to achieve malaria elimination by 2030 [2]. While the concept of eliminating malaria is bold, there are 100 endemic countries with continuous malaria transmission and the main concern is malaria transmission re-introduction in malaria-free areas worldwide through population movement with endemic countries [3], e.g., in eastern Mediterranean region, re-introduction of malaria has occurred more than once in countries that had been free from malaria [3].

To reduce local cases and to maintain elimination status, the focus should be on monitoring receptivity, vulnerability, and health system capacity [4]. There is enough evidence to support the role of health systems in monitoring malaria disease through early case detection and appropriate response to prevent re-introduction, especially in malaria-prone areas [5-8]. In this regard, to prevent re-introduction of malaria transmission and malaria outbreaks, factors triggering transmission, such as human, vector and parasite factors, should regularly be monitored [9].

Resorting to new tools to monitor susceptibility to malaria occurrence is inevitable [10]. Numerous studies were conducted for prediction of malaria epidemics in endemic countries and the necessity for malaria early warning systems (MEWS) has been emphasized [11, 12]. Accordingly, in malaria control settings, variables such as population movement, minimum and maximum temperatures, rainfall, and humidity were suggested when designing MEWS [13-15]. Each country is exposed to particular and different ecological circumstances; challenges are more apparent at local level when using similar indicators to predict malaria occurrence [16]. A limited number of studies focus on a comprehensive approach for early warning, which considers predictive factors rather than meteorological variables [17]. This is a crucial issue in pre-elimination and elimination settings where variables other than meteorological are more important. However, only a handful of studies have focused on forecasting malaria outbreaks or re-introduction in elimination settings $[13,14,18]$.

Iran started its malaria elimination programme in 2009 and has experienced a dramatic decline in the number of malaria cases over the last 6 years. As highlighted in its National Strategic Plan for Malaria Elimination, one of the main concerns to achieve malaria elimination is how to prevent re-introduction malaria transmission. This study aimed to design an applicable model for preelimination and elimination settings to assess a comprehensive list of predicting factors for re-introduction in malaria-prone areas and to predict the possibility of malaria outbreaks.

\section{Methods}

\section{Malaria situation in Iran: study area}

A mixed method study was undertaken in a pre-elimination setting in Sistan and Baluchistan Province. The province is populated by around 2.5 million persons, of whom $51 \%$ are rural. According to the human development index (HDI), it is the most underdeveloped region in Iran, with the highest rate of population growth [19]. About $14 \%$ of rural households have no access to electricity [20]. In 2013, around $84 \%$ of foci with local transmission were located in this province, where both Plasmodium vivax and Plasmodium falciparum have been reported; $10 \%$ were estimated to be $P$. falciparum. Due to the implementation of elimination strategy, the local transmission was limited to less than $3 \%$ of rural foci in Sistan and Baluchestan in 2013, the majority with a population of less than 400. Malaria in this region follows an unstable pattern with two transmission seasons: from March to May, and from July to October, with annual average temperature and relative humidity ranging from 22 to $37^{\circ} \mathrm{C}$ and 31 to $76 \% \min$ and max, respectively, based on district ground synoptic weather stations reports [21]. The area borders malaria-endemic regions of Afghanistan and Pakistan, where population movement between Iran, Afghanistan and Pakistan is a routine practice, with its consequent risk of re-introduction. Moreover, the presence of marginalized people on low income, with high rate of illiteracy, limited access to air-conditioning systems, the climatic conditions, and the presence of the main vectors, makes this region a highrisk area for malaria transmission.

Since the Malaria Elimination Programme has been undertaken in Iran, everybody has access to free of charge, active and passive case-finding services, the minimum of annual blood examination rate (ABER) in the study areas for the period of 2008-2013 was $18 \%$ [22]. In addition, the early detection system for timely and complete reporting of detected malaria cases had been established for more than a decade. Therefore, missing a re-introduced case seems a very unlikely possibility.

\section{Variable identification process, checklist design and field study}

To develop a checklist of 20 explanatory variables, the nominal group technique was used by a group consisting of epidemiologists, entomologists, parasitologists, 
clinicians, and health system specialists with at least 5 years' field experience in malaria areas, together with a literature review of international and national sources (databases of PubMed, ScienceDirect, Scopus, Web of Science, Iranmedex, Sientific Information Database) was conducted. The keywords for the literature review were 'malaria' in conjunction with 're-introduction, 'elimination, 'outbreak,, 'forecast', 'MEWS, 'transmission,' 'meteorological variables', and 'population movement'. In order to develop a user-friendly model for applicants in the field, three sub-categories for each variable were considered, each indicating its impact severity (a range of high, moderate, low) on triggering re-introduction and malaria outbreaks. The checklist included five main components: (1) parasite variables; (2) history of malaria and other disease outbreaks in the focus; (3) access to the health services; (4) meteorological variables; and, (5) vector variables (see Additional file 1: questionnaire). Next, 33 rural foci affected by re-introduction of malaria transmission were selected once in a six-year period from March 2008 to March 2013. In this study, a focus was considered to be 'a defined and circumscribed locality situated in a currently or formally malarious area and containing the continuous or intermittent epidemiological factors necessary for malaria transmission' [23], and re-introduction of malaria transmission was considered to be 'resurgence of malaria transmission (P. falciparum or P. vivax, or both) in a cleared-up focus'. Cleared-up foci were defined as 'foci with no history of malaria transmission within the previous 36 months. The inclusion criterion for selecting a focus affected by re-introduction was the occurrence of locally transmitted malaria case(s) during three successive weeks.

For each selected focus with re-introduction, a clearedup focus with no history of local malaria cases during the previous 3 years was selected as a paired control focus to find triggering variables for re-introduction and to exclude interfering environmental factors, particularly meteorological variables. These paired control foci were located the closest possible distance from the foci affected by re-introduction and with a similar range of population (Fig. 1). Considering the similarity of geographical and the meteorological condition between focus affected by re-introduction and paired control, the affected focus with re-introduction were compared against its condition at the same period in the previous year when the focus had been classified as cleared-up with no report of local cases.

In the next step, a training event was conducted and the checklist was introduced by the research team to a new group of experienced staff with at least 10 years' experience in the field of malaria, in addition to their educational background of entomology and epidemiology. The checklist was filled out in the field for an affected focus by re-introduction and also for its paired control focus. The checklist was completed in two different time periods for the focus affected by re-introduction: (1) for a period of 12 weeks prior to diagnosis of the first case after the reintroduction; and, (2) for the same period (for 12 weeks) the previous year with no case reports. In addition, it was completed for the paired control focus for 12 weeks coinciding with the resurgence of malaria transmission in the focus.

\section{Weighting process for variables}

Given data from the field study and collecting the meteorological data from district ground synoptic weather stations, sub-categories of each variable were weighted by an expert group, with numerical values ranging from 0.01 to 10 (weakest to strongest predictors of the epidemic in next 8 weeks, respectively) based on relative frequency difference between the affected and control foci. The sum of sub-category values for each variable was considered to be $9(100 \%)$. Finally, based on the weights for the subcategories, 20 selected variables, using pair-wise comparison matrix, were prioritized in view of their impact on triggering re-introduction of malaria transmission by Expert Choice software version 11 suggested by analytic hierarchical process (AHP) [24, 25].

\section{Mathematical approach}

According to AHP output, once the hierarchy was made, the most effective variable (named $\varnothing$ ) with the highest score was defined as a trigger of malaria re-introduction and outbreak. To define critical thresholds of four categories for stratification of the risk of re-introduction as well as an epidemic, $19 \mathrm{~L}$-shaped matrices of $3 \times 3$ cells were made, the product of sub-categories of $\varnothing$ on other variables (named $\Theta$ 's) were determined (see Additional file 2: Product of weights). The matrix was developed based on idea of Haddon matrix, which is used by public health decision-makers, especially in injury prevention settings [26]. Haddon matrix output is a qualitative analysis of emergent conditions which was added to an innovative mathematical approach to analyse and interpret the model output in a quantitative manner. In the second step, the geometric means (GMs) for corresponding cells of 19 matrixes were calculated by sub-category scores of $\Theta$ and $\varnothing$ (see Additional file 3: Geometric mean calculation).

Four strata for the risk of malaria re-introduction or epidemics were obtained where:

- GM for the matrix cells of $\varnothing \mathrm{L} \times$ $\times$ iiL and $\varnothing \mathrm{L} \times$ $\times$ iM were considered as lower and upper bounds of "low risk of re-introduction' range, respectively; 


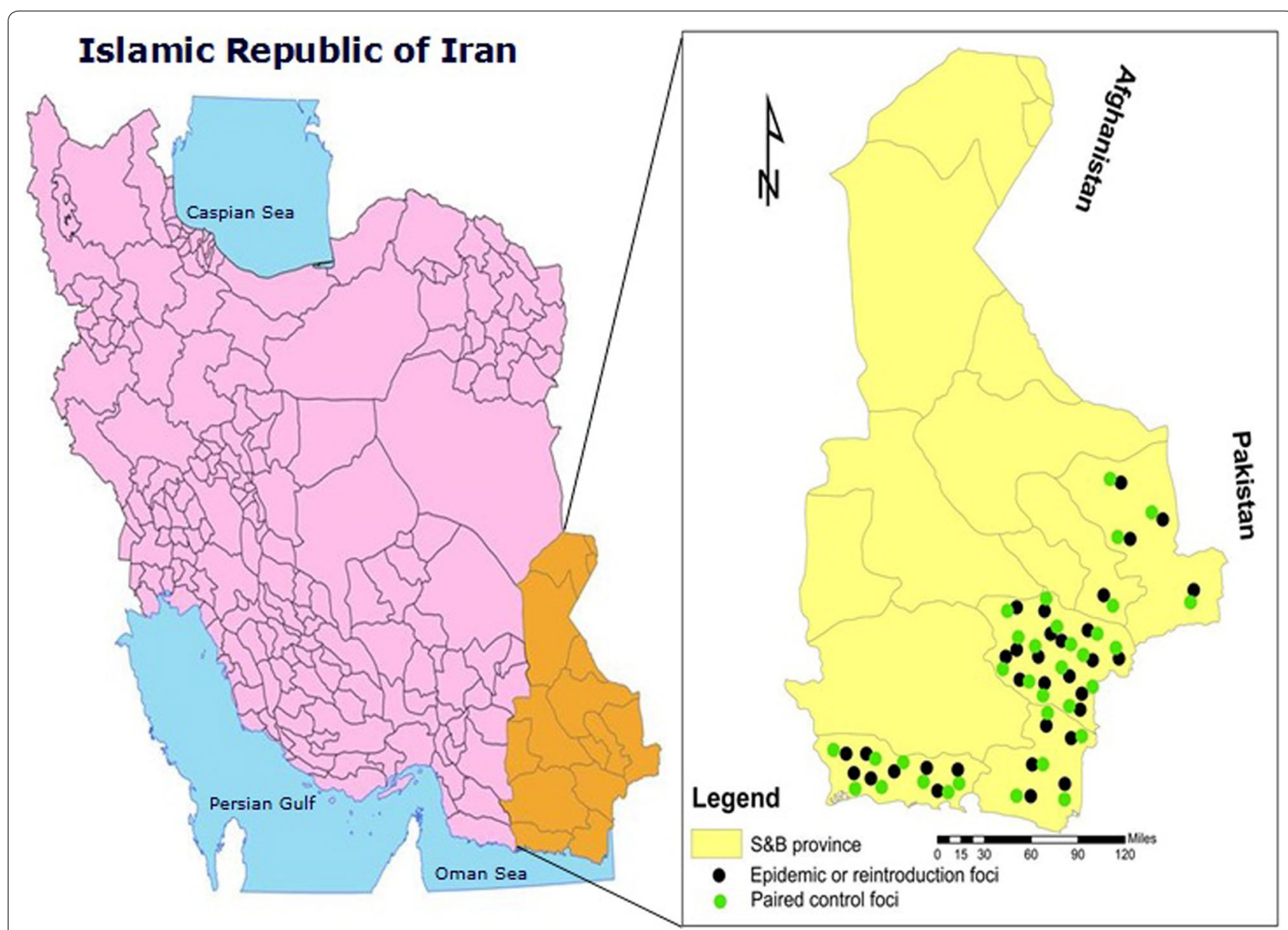

Fig. 1 A map of the study area in Sistan and Baluchistan province showing affected and paired control foci

- $\mathrm{GM}$ for the matrix cells of $\varnothing \mathrm{H} \times \Theta i L$ and $\varnothing \mathrm{M} \times$ ӨiM were considered as lower and upper bounds of 'mild risk of re-introduction' range, respectively;

- $\mathrm{GM}$ for the matrix cells of $\varnothing \mathrm{M} \times \Theta i M$ and $\varnothing \mathrm{H} \times$ OiM were considered as lower and upper bounds of 'moderate risk of outbreak' range, respectively;

- GM for the matrix cells of $\varnothing \mathrm{H} \times$ ӨiM and $\varnothing \mathrm{H} \times$ $\mathrm{OiH}$ were considered as lower and upper bounds of 'high risk of outbreak' range, respectively.

$$
\theta_{i} ; i=1, \ldots, 19
$$

\section{Calibration of the model}

Using R software version 3.1.3, for any given stratum of $\varnothing, 90$ repeated random samples of remaining 19 variables ( $\Theta$ 's) were generated in their similar sub-categories of high, moderate and low. The sampling was done with three different probabilities of 10-20, 21-79 and 80-90\% and their complementary probabilities for $\Theta \mathrm{i}($ e.g., at $\varnothing \mathrm{H}$, ten repeated random samples of $\mathrm{\Theta iH}$ with probability of $80 \%$ and complementary probability, $20 \%$, for other variables of $\Theta \mathrm{iM}$ in a category of moderate risk, were selected). Finally, 270 random samples with different risk sets, the numbers of GM scores with similar results in the range of four risk prediction categories proposed by the model (GMs in the similar range of each defined risk category of re-introduction and outbreaks prediction) were considered as the cut-offs for accuracy.

\section{The model sensitivity and specificity}

To determine the model sensitivity and specificity, a retrospective case-control study was conducted using the National Database of Malaria Foci from 2014 to 2015. Accordingly, 20 foci with re-introduction of malaria were randomly selected from different districts in Iran. In addition, data of all seven foci with malaria outbreaks in 2014 and 2015 (with four to nine local cases of either falciparum or vivax malaria reported) were used. Also, in malaria-free zones in Iran, which had no re-introduction after 1 year since the last reported case, 27 foci with imported malaria cases from abroad were randomly selected and the specificity of the model was determined. 


\section{Results}

Table 1 shows 20 explanatory variables that were introduced based on comparing the situation of focus affected by re-introduction with the situation of the same focus 12 months ago, and comparing it with the control focus nearby. Any changes in the 20 selected predicting variables has been considered to be the affecting factors which may cause re-introduction and malaria outbreaks.

As shown in Fig. 2, based on AHP scores with inconsistency ratio of less than $10 \%$, 'population movement of a target focus with endemic areas' was determined as the pivotal factor (AHP score: 0.181). Moreover, 'quality of population movement in a target focus' (AHP score: 0.114), 'following malaria transmission season' (AHP score: 0.088 ), 'average daily minimum temperature in the previous 8 weeks' (AHP score: 0.062), 'outdoor resting shelter for malaria vectors in a target focus' (AHP score: $0.045)$, and 'total of rainfall during the previous 8 weeks' (AHP score: 0.042 ), were determined, based on predictive values.

Tables 2, 3, 4, 5 and 6 show multiplicative interaction matrix of parasite reservoir, infrastructures and meteorological and entomological variables by three subcategories of 'population movement'. In this regard, unauthorized immigrants to Iran from malaria-endemic countries, who had no permanent address and were ambulant, no access of suspected cases in the focus to malaria diagnosis services, the average of daily maximum temperature in the previous 8 weeks, outdoor resting shelter for malaria vectors in a target focus and if the following transmission season is March to October, scored highest for malaria re-introduction and outbreak prediction.

\section{Calibration of the model}

Figure 3 shows the accuracy of the malaria early warning tool improvising various scenarios for explanatory variables with different probabilities. The Figure consists of three main sections based on population movement strata $(\varnothing)$ including low, moderate and high (bottom row of Figure). The middle and upper rows of the Figure refer to other variables $(\Theta i)$.

\section{Interpretation of low population movement strata}

For a focus with no population movement (as a low-risk stratum), in the presence of different probability sets of other variables, $100 \%$ (90/90 repeated samples) of GMs are in the range of low risk of re-introduction (green).

\section{Interpretation of moderate population movement strata}

In a focus in moderate-risk stratum of population movement, in the presence of other variables with different probabilities, more than $44 \%$ of GMs (40/90) are in the range of mild risk of re-introduction (yellow). In addition, in the presence of other related variable sets in high-risk strata, less than $32 \%$ of GMs (28/90) are in the range of moderate risk of malaria outbreaks (orange). Fewer than $3 \%$ of set samples $(2 / 90)$ are red (in the case of set samples with $80 \%$ of $\Theta \mathrm{iH}$ and $20 \%$ of $\Theta \mathrm{iM})$, i.e., unadjusted in the range of moderate risk of malaria outbreaks.

\section{Interpretation of high population movement strata}

For high-risk stratum of population movement, in the presence of other related sets of variables with different probabilities, $32 \%$ (29/90) of GMs are in the range of high risk of outbreak (red), and fewer than $8 \%(7 / 90)$ of GMs are out of range of defined epidemic risk categories. In total, 220 out of 270 tests $(81.4 \%)$ were ranked in the range of defined risk categories of re-introduction or malaria outbreaks as proposed by the model (the bars in the same colour).

\section{Sensitivity and specificity of model}

Table 7 shows frequency of risk strata in foci located in different zones of Iran during 2014-2015. Accordingly, the GM scores of risk assessments by the model in foci with a history of re-introduction fall into the ranges of mild risk of re-introduction and moderate risk of reintroduction and the GM scores of risk assessments in foci with a history of outbreak fall into the range of high risk of malaria epidemic (sensitivity $=100 \%$ and positive predictive value of $81.8 \%$ ). In addition, the GM scores for control foci fall into the ranges of low risk of malaria re-introduction, and mild risk of malaria re-introduction (specificity $=77 \%$ and negative predictive value of $100 \%)$.

\section{Discussion}

The study highlights predisposing factors of malaria reintroduction and outbreaks in high-risk prone areas in Iran, which is in a pre-elimination setting. The study introduced a new, simple, statistical model to predict malaria re-introduction and outbreaks, with positive predictive value $(81.8 \%)$ and negative predictive value (100\%). It incorporates different sets of comprehensive lists of predictive variables in a multiplicative, interactive manner that can be used by decision-makers and endusers at peripheral level to predict malaria re-introduction 8 weeks in advance. Using a tool that can be designed based on a model enables a health system to prioritize allocation of its resources and take necessary action early enough to prevent resurgence of malaria in areas that are already cleared-up but at risk of re-introduction of transmission. Considering this study's results and proposed methodology, the model can be adjusted based on local circumstances in other countries in order to develop a 


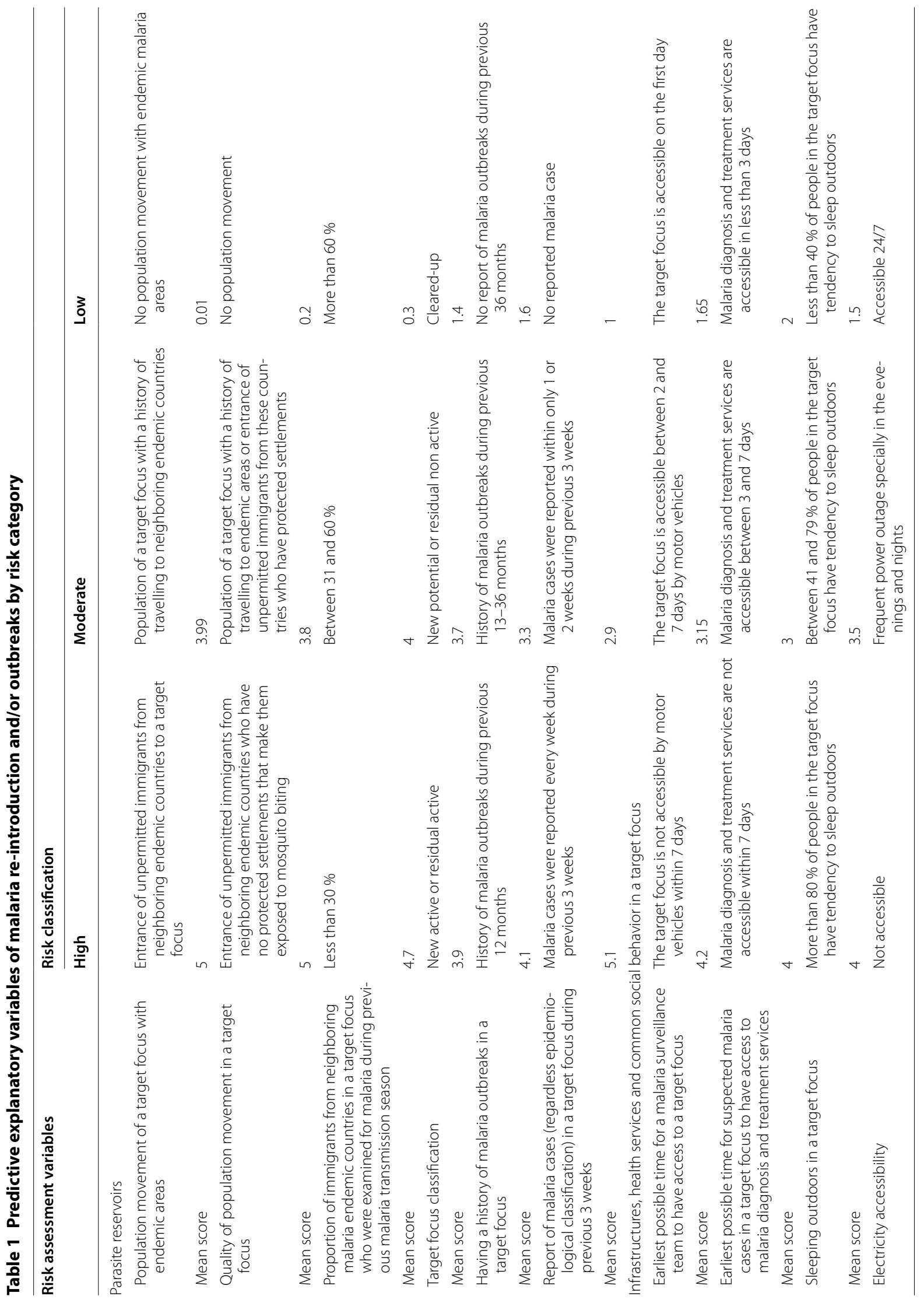




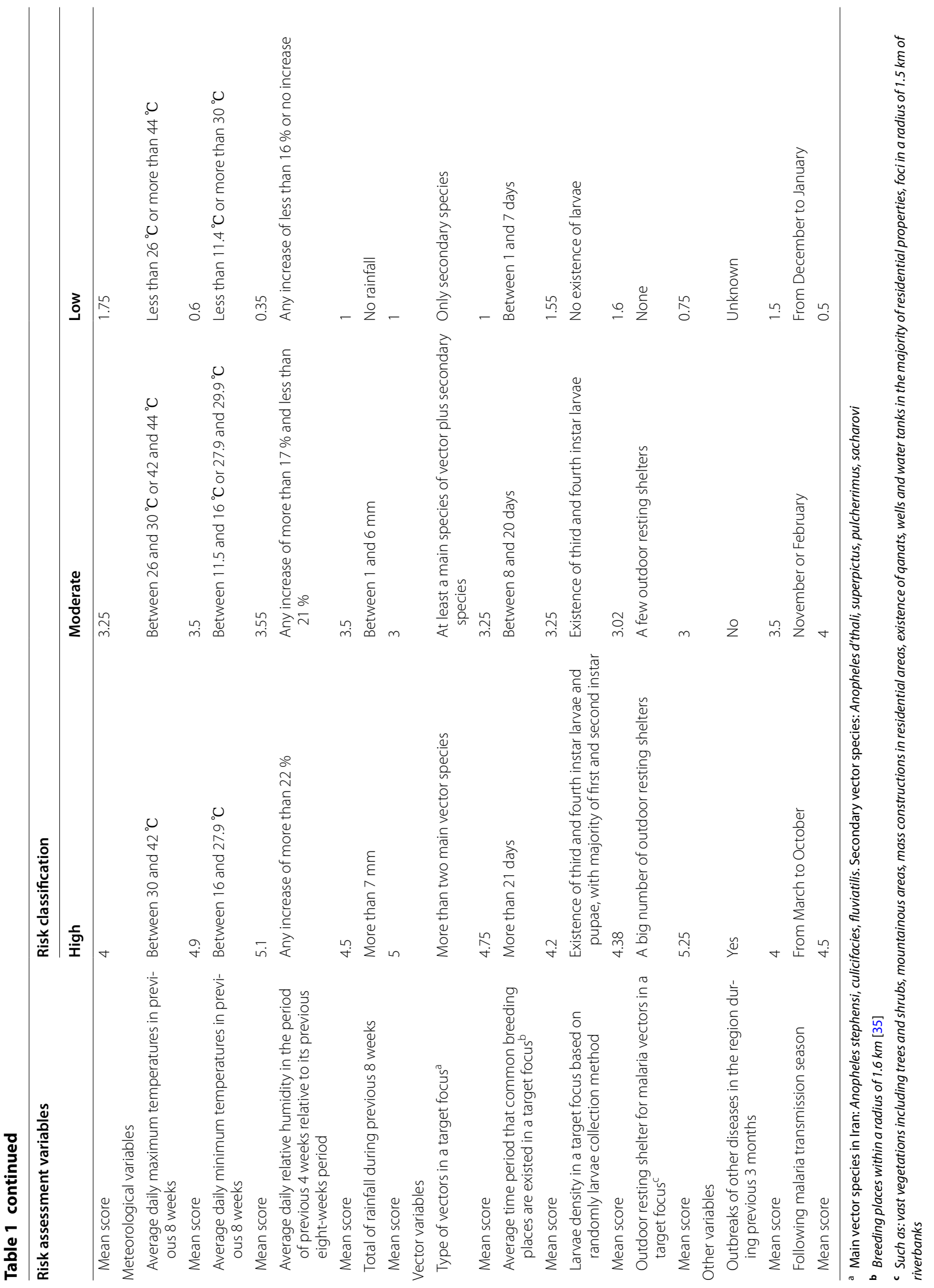




\begin{tabular}{|c|c|c|}
\hline Privities with respect to: & & \\
\hline Population morement & .181 & \\
\hline Qualty of population movements & .114 & \\
\hline Forecast period of Malaria transmission potential & .088 & \\
\hline Proportion of immigrants from Malaria endemic countries & $.063 \mathrm{I}$ & \\
\hline The average maximun temperature in last month & .052 & \\
\hline The average minimum temperature in last month & .052 & \\
\hline Extrinsic shelter of resting the vectors & .045 & \\
\hline Raining & .042 & \\
\hline Type of Yector & .039 & \\
\hline Having a history of Malania outbreak in focus & .038 & \\
\hline Case report of Malaria cases & .036 & \\
\hline Humidity & .032 & \\
\hline Larvae density & .028 & \\
\hline Average of duration of existence of common breeding places in the focus & .027 & \\
\hline Focus classtication & .026 & \\
\hline Sleeping out of home of residence of focus & .025 & \\
\hline Access of Malaria sunveilance team to the focus & 019 & \\
\hline Time period for access of suspected cases in the focus to malania diagnosis services & 019 & \\
\hline Power accessibility & .019 & \\
\hline $\begin{array}{l}\text { Qutbreaks of other disease in given region during bst three months of malaria rentroduction } \\
0 \text { missing judgments. }\end{array}$ & .014 & \\
\hline Fig. 2 Predictive variables of malaria re-introduction weightec & & nd prioritized by analytical hierarchical process scores \\
\hline
\end{tabular}

Table 2 Multiplicative interaction model of parasite reservoir variables and most deterministic factor of malaria reintroduction by risk classification

\begin{tabular}{|c|c|c|c|c|}
\hline \multirow[t]{2}{*}{ Parasite reservoir variables } & \multicolumn{4}{|c|}{$\begin{array}{l}\text { Population movement of a target } \\
\text { focus with endemic areas }(\varnothing)\end{array}$} \\
\hline & Risk category & High & Moderate & Low \\
\hline \multirow{3}{*}{$\begin{array}{l}\text { Quality of population } \\
\text { movement in a target focus }\end{array}$} & High & 25 & 19 & 1 \\
\hline & Moderate & 19.5 & 14.82 & 0.78 \\
\hline & Low & 0.5 & 0.38 & 0.02 \\
\hline \multirow{3}{*}{$\begin{array}{l}\text { Proportion of immigrants } \\
\text { from neighboring malaria } \\
\text { endemic countries in a } \\
\text { target focus who were } \\
\text { examined for malaria during } \\
\text { last malaria transmission } \\
\text { season }\end{array}$} & High & 23.5 & 20 & 1.5 \\
\hline & Moderate & 18.33 & 15.6 & 1.17 \\
\hline & Low & 0.47 & 0.4 & 0.03 \\
\hline \multirow{3}{*}{$\begin{array}{l}\text { Having a history of malaria } \\
\text { outbreaks in a target focus }\end{array}$} & High & 20.5 & 16.5 & 8 \\
\hline & Moderate & 15.99 & 12.87 & 6.24 \\
\hline & Low & 0.41 & 0.33 & 0.16 \\
\hline \multirow{3}{*}{$\begin{array}{l}\text { Report of malaria cases } \\
\text { (regardless epidemiological } \\
\text { classification) in a target } \\
\text { focus during last } 3 \text { weeks }\end{array}$} & High & 25.5 & 14.5 & 5 \\
\hline & Moderate & 19.89 & 11.31 & 3.9 \\
\hline & Low & 0.51 & 0.29 & 0.1 \\
\hline \multirow[t]{3}{*}{ Target focus classification } & High & 19.5 & 18.5 & 7 \\
\hline & Moderate & 15.21 & 14.43 & 5.46 \\
\hline & Low & 0.39 & 0.37 & 0.14 \\
\hline
\end{tabular}

customized model to meet their requirements. Some of variables that were introduced in the study, including 'outdoor resting shelter for malaria vectors in a target
Table 3 Multiplicative interaction model of community infrastructure variables and most deterministic factor of malaria reintroduction by risk classification

\begin{tabular}{|c|c|c|c|c|}
\hline \multirow{2}{*}{$\begin{array}{l}\text { Infrastructures, health ser- } \\
\text { vices and common social } \\
\text { behavior in a given focus }\end{array}$} & \multicolumn{4}{|c|}{$\begin{array}{l}\text { Population movement of a target } \\
\text { focus with endemic areas }(\varnothing)\end{array}$} \\
\hline & Risk category & High & Moderate & Low \\
\hline \multirow{3}{*}{$\begin{array}{l}\text { Earliest possible time for a } \\
\text { malaria surveillance team } \\
\text { to have access to a target } \\
\text { focus }\end{array}$} & High & 21 & 15.75 & 8.25 \\
\hline & Moderate & 16.38 & 12.285 & 6.435 \\
\hline & Low & 0.42 & 0.315 & 0.165 \\
\hline \multirow{3}{*}{$\begin{array}{l}\text { Earliest possible time for } \\
\text { suspected malaria cases } \\
\text { in a target focus to have } \\
\text { access to malaria diagnosis } \\
\text { and treatment services }\end{array}$} & High & 21 & 15.75 & 8.25 \\
\hline & Moderate & 16.38 & 12.285 & 6.435 \\
\hline & Low & 0.42 & 0.315 & 0.165 \\
\hline \multirow[t]{3}{*}{ Electricity accessibility } & High & 20 & 16.25 & 8.75 \\
\hline & Moderate & 15.6 & 12.675 & 6.825 \\
\hline & Low & 0.4 & 0.325 & 0.175 \\
\hline \multirow{3}{*}{$\begin{array}{l}\text { Sleeping outdoors in a target } \\
\text { focus }\end{array}$} & High & 20 & 17.5 & 7.5 \\
\hline & Moderate & 15.6 & 13.65 & 5.85 \\
\hline & Low & 0.4 & 0.35 & 0.15 \\
\hline
\end{tabular}

focus', 'quality of population movement in a target focus', 'duration average of common breeding places existing in a target focus', and 'larvae density in a target focus based on randomly larvae collection method, were novel predicting factors for malaria outbreaks particulalry in elimiantion setting. 
Table 4 Multiplicative interaction model of meteorological variables and most deterministic factor of malaria reintroduction by risk classification

\begin{tabular}{|c|c|c|c|c|}
\hline \multirow[t]{2}{*}{$\begin{array}{l}\text { Meteorological variables } \\
(\Theta)\end{array}$} & \multicolumn{4}{|c|}{$\begin{array}{l}\text { Population movement of a target } \\
\text { focus with endemic areas }(\varnothing)\end{array}$} \\
\hline & Risk category & High & Moderate & Low \\
\hline \multirow{3}{*}{$\begin{array}{l}\text { Average daily maximum } \\
\text { temperatures in previous } \\
8 \text { weeks }\end{array}$} & High & 24.5 & 17.5 & 3 \\
\hline & Moderate & 19.11 & 13.65 & 2.34 \\
\hline & Low & 0.49 & 0.35 & 0.06 \\
\hline \multirow{3}{*}{$\begin{array}{l}\text { Average daily minimum } \\
\text { temperatures in previous } \\
8 \text { weeks }\end{array}$} & High & 25.5 & 17.75 & 1.75 \\
\hline & Moderate & 19.89 & 13.845 & 1.365 \\
\hline & Low & 0.51 & 0.355 & 0.035 \\
\hline \multirow{3}{*}{$\begin{array}{l}\text { Total of rainfall during } \\
\text { previous } 8 \text { weeks }\end{array}$} & High & 25 & 15 & 5 \\
\hline & Moderate & 19.5 & 11.7 & 3.9 \\
\hline & Low & 0.5 & 0.3 & 0.1 \\
\hline \multirow{3}{*}{$\begin{array}{l}\text { Average daily relative } \\
\text { humidity in the period of } \\
\text { previous } 4 \text { weeks relative } \\
\text { to its previous } 8 \text { weeks } \\
\text { period }\end{array}$} & High & 22.5 & 17.5 & 5 \\
\hline & Moderate & 17.55 & 13.65 & 3.9 \\
\hline & Low & 0.45 & 0.35 & 0.1 \\
\hline
\end{tabular}

Table 5 Multiplicative interaction model of entomological variables and most deterministic factor of malaria reintroduction by risk classification

\begin{tabular}{lllll}
\hline Vector variables $(\Theta)$ & \multicolumn{4}{l}{$\begin{array}{l}\text { Population movement of a target } \\
\text { focus with endemic areas }(\varnothing)\end{array}$} \\
\cline { 2 - 5 } & Risk category & High & Moderate & Low \\
\hline Average time period that & High & 21 & 16.25 & 7.75 \\
$\begin{array}{c}\text { common breeding places } \\
\text { are existed in a target }\end{array}$ & Moderate & 16.38 & 12.675 & 6.045 \\
focus & Low & 0.42 & 0.325 & 0.155 \\
Larvae density in a target & High & 21.9 & 15.1 & 8 \\
focus based on randomly & Moderate & 17.082 & 11.778 & 6.24 \\
larvae collection method & Low & 0.438 & 0.302 & 0.16 \\
Type of vectors in a target & High & 23.75 & 16.25 & 5 \\
focus & Moderate & 18.525 & 12.675 & 3.9 \\
& Low & 0.475 & 0.325 & 0.1 \\
Outdoor resting shelter for & High & 26.25 & 15 & 3.75 \\
malaria vectors in a target & Moderate & 20.475 & 11.7 & 2.925 \\
focus & Low & 0.525 & 0.3 & 0.075 \\
\hline
\end{tabular}

This analysis confirms results from previous studies which indicate that population movement within endemic areas is a key factor for re-introduction of malaria transmission $[15,27]$. Based on this study's findings, population movement, especially with neighbouring endemic countries is the most potential predisposing factor of malaria re-introduction in Iran. While quantifying population movement is a daunting task [4], this study shows that the quality of population movement from
Table 6 Multiplicative interaction model of other related variables and most deterministic factor of malaria reintroduction by risk classification

\begin{tabular}{lllll}
\hline Other variables $(\Theta)$ & \multicolumn{4}{l}{$\begin{array}{l}\text { Population movement of a target } \\
\text { focus with endemic areas }(\varnothing)\end{array}$} \\
\cline { 2 - 5 } & Risk category & High & Moderate & Low \\
\hline Outbreaks of other diseases in & High & 20 & 17.5 & 7.5 \\
the region during previous & Moderate & 15.6 & 13.65 & 5.85 \\
3 months & Low & 0.4 & 0.35 & 0.15 \\
Following malaria transmission & High & 22.5 & 20 & 2.5 \\
season & Moderate & 17.55 & 15.6 & 1.95 \\
& Low & 0.45 & 0.4 & 0.05 \\
\hline
\end{tabular}

endemic areas is of paramount importance, especially when the domicile of a population is missing.

Studies focused on forecasting malaria outbreaks or re-introduction in elimination settings are rare. The results of a study in Spain confirm that seasonality can be an important effective variable in increasing transmission risk. That study showed maximum normalized difference vegetation index (NDVI) values in rice-field areas along with an increase in transmission risk in the period from May to September for P. falciparum, and from May to October for $P$. vivax. In addition, it emphasized that an increase in temperature did not mean a malaria transmission risk if accompanied by a precipitation decrease [18]. This favours the study approach to including meteorological variables, such as temperature, precipitation and humidity, in the model. There is enough evidence to support the role of meteorological variables, including rainfall, humidity, maximum and minimum temperatures, in early detection of malaria epidemics through the adaptation of humans, vectors and Plasmodium [22, 28-31]. Nevertheless, the advantage of climate data per se in malaria incidence prediction is eclipsed by significant uncertainties due to the complexity of ecological indicators, especially in largescale geographical extents [16]. Other studies stressed the role of environmental variables in malaria transmission and found other variables rather than climatic factors, such as vegetation index, number of malaria cases within the previous month before the prediction, and socio-economic status [32-34].

Given the positive predictive value of the more than $80 \%$ and negative predictive value $100 \%$, it shows an acceptable level of sensitivity of the model that is a requirement for pre-elimination and elimination settings where the programme should react to every possible active foci. In addition, it will support decision-makers in preventing wasting of resources on foci that are at zero risk of re-introduction. 


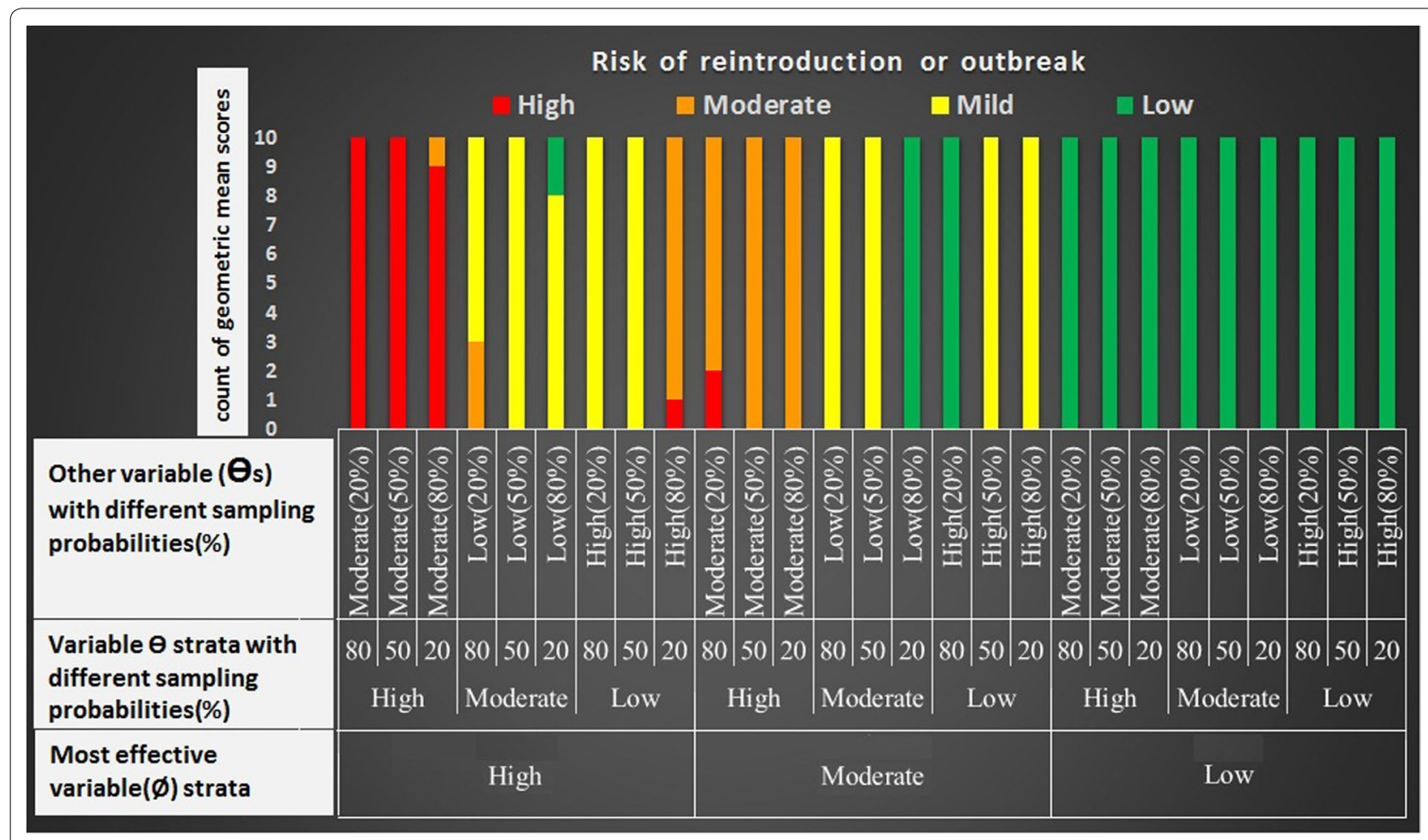

Fig. 3 Model calibration tested by resampling different sets of explanatory variables to forecast re-introduction and/or outbreak in a focus

Table 7 Risk assessment of foci with a history of reintroduction, outbreak and also malaria free (control) to determine sensitivity, specificity, positive and negative predictive values of the model

\begin{tabular}{|c|c|c|c|c|c|}
\hline Risk category & High & & Moderate & Low & Range of GM scores \\
\hline \multicolumn{6}{|l|}{ Foci classification } \\
\hline Reintroduction & $136(34 \%)$ & & $149(37.2 \%)$ & $115(28.8)$ & $9.08-16.35$ \\
\hline Outbreak & $71(50.7 \%)$ & & $56(40 \%)$ & $13(9.3 \%)$ & $17.02-18.96$ \\
\hline Control & 65 (12.1\%) & & $80(14.8 \%)$ & $395(73.1 \%)$ & $0.14-5.98$ \\
\hline Foci classification & & Outbreak & Reintroduction & Control & \\
\hline \multicolumn{6}{|l|}{ Test } \\
\hline+ & & 7 & 20 & 6 & \\
\hline- & & 0 & 0 & 21 & \\
\hline Total & & 7 & 20 & 27 & \\
\hline Sensitivity (\%) & & $100 \%$ & $100 \%$ & - & \\
\hline Specificity (\%) & & - & - & $77 \%$ & \\
\hline Positive predictive value (\%) & & $81.8 \%$ & & - & \\
\hline Negative predictive value (\%) & & - & & $100 \%$ & \\
\hline
\end{tabular}

Following the development of the model to be used in the field, an action plan has been developed to prevent malaria re-introduction/outbreaks. It proposes interventions that should be implemented once the model conveys a risk of re-introduction/outbreaks, e.g., a full service coverage for a focus population, particularly immigrants by early case finding and prompt treatment, enhancement of surveillance team access to a focus, distribution of long-lasting insecticide-treated bed nets to those sleeping outdoors in a target focus, larval source management to eliminate breeding places, as well as adult vector control measures to reduce vectorial capacity of focus. 


\section{Study limitations}

Given that the study area is in a pre-elimination setting, a limited number of foci with a history of re-introduction were reported, therefore, the sample size was small. In addition, there are discrepancies between the defined range of temperature and humidity in the model with the theoretical basis of malaria transmission. The reason is that the model was managed to be applicable based on accessible data in the field, i.e., the monthly averages of meteorological data were extracted from ground synoptic weather stations as proximal variables, taking into account the probable systematic errors of the measures. Moreover, the study assumes only a two-dimensional interaction assessment of variables, while it does not take inherent associations of the variables into consideration as well as their probability distributions.

\section{Conclusion}

This study introduced a new, simple, statistical model to forecast malaria re-introduction and outbreak risks in pre-elimination and elimination settings following population movement of the focus with malaria-endemic areas. The model incorporates comprehensive deterministic factors, including 20 variables that are accessible in the field and are easily analysed in an interactive manner. This provides an evidence-based prediction for malaria re-introduction and outbreaks 8 weeks in advance with positive predictive value of $81.8 \%$, thereby allowing for effective and timely interventions.

\section{Additional files}

Additional file 1. An overview of the questioner for gathering information in foci affected by reintroduction of malaria transmission/outbreak.

Additional file 2. Product of weights.

Additional file 3. Geometric mean calculation.

\section{Abbreviations}

HDI: human development index; AHP: analytic hierarchical process; GM: geometric mean; MEWS: malaria early warning system; ABER: annual blood examination rate; NDVI: normalized difference vegetation index.

\section{Authors' contributions}

MR and GK had full access to all the data in the study and take responsibility for the integrity of the data and the accuracy of the data analysis; MR, AS and GK: study concept, design and supervision; MR, GK and MA: acquisition of data; GK, MR, AS, and MM: analysis and interpretation of data; MR, GK and MM: statistical analysis; MR, AS, GK, MA, and SMT: administrative, technical, or material support; MR, AS, GK, MA, SMT, and MM: drafting of the manuscript and critical revision of the manuscript for important intellectual content. All authors read and approved the final manuscript.

\section{Author details}

${ }^{1}$ Center for Vectors and Vector-Borne Diseases, Department of Biology, Mahidol University, Bangkok, Thailand. ${ }^{2}$ Zanjan Social Determinants of Health Research Centre, Zanjan University of Medical Silences and Health Services, Zanjan, Iran. ${ }^{3}$ Epidemiology Department, School of Public Health, Shahid Beheshti University of Medical Silences and Health Services, Tehran, Iran.
${ }^{4}$ Infectious Diseases and Tropical Medicine Research Center, School of Public Health, Zahedan University of Medical Sciences, I.R. of Iran, Zahedan, Iran. ${ }^{5}$ Independent Malaria Consultant, Tehran, Iran. ${ }^{6}$ Health Promotion Research Center, Zahedan University of Medical Sciences, Zahedan, Iran. ${ }^{7}$ Present Address: Independent Malaria Consultant, Member of Surveillance, Monitoring and Evaluation Technical Expert Group, Global Malaria Programme, WHO, Geneva, Switzerland.

\section{Acknowledgements}

We thank colleagues in the Malaria Elimination Programme in the southeast of Iran for facilitating field visits,

\section{Competing interests}

The authors declare that they have no competing interests.

Received: 22 November 2015 Accepted: 23 February 2016

Published online: 02 March 2016

\section{References}

1. WHO. World malaria report 2014. Geneva: World Health Organization; 2014. http://www.who.int/malaria/publications/world_malaria_ report_2014/wmr-2014-no-profiles.pdf. Accessed 25 Oct 2015.

2. WHO. Global technical strategy for malaria 2016-2030. Geneva: World Health Organization; 2015. https://www.google.com/?gws_rd=ssl\#q=Glo bal+technical+strategy+for+malaria+2016-2030. Accessed 25 Oct 2015.

3. WHO. Guidelines on prevention of the re-introduction of malaria. World Health Organization Regional Office for the Eastern Mediterranean. Cairo, 2007. http://applications.emro.who.int/dsaf/dsa743.pdf. Accessed 25 Oct 2015.

4. Feachem R, Phillips AA. Targett F+GAT, on behalf of the Malaria Elimination Group, Shrinking the malaria map: a guide on malaria elimination for policy makers. The Global Health Group, Global Health Sciences, University of California, San Francisco, 2009. http://r4d.dfid.gov.uk/PDF/ Outputs/Targets_RPC/FeachemMEG\%28Lines\%29April09.pdf. Accessed 25 Oct 2015.

5. WHO. Malaria elimination: a field manual for low and moderate endemic countries. Geneva: World Health Organization; 2007. http://apps.who.int/ iris/bitstream/10665/43796/1/9789241596084_eng.pdf. Accessed 25 Oct 2015.

6. WHO. From malaria control to malaria elimination: A manual for elimination scenario planning. Global Malaria Programme. Geneva: World Health Organization; 2014. http://apps.who.int/iris/bitstr eam/10665/112485/1/9789241507028_eng.pdf. Accessed 25 Oct 2015.

7. Barclay V, Smith R, Findeis J. Surveillance considerations for malaria elimination. Malar J. 2012;11:304. doi:10.1186/1475-2875-11-304.

8. Tambo E, Ai L, Zhou X, Chen J, Hu W, Bergquist R, et al. Surveillanceresponse systems: the key to elimination of tropical diseases. Infect Dis Poverty. 2014;3:17.

9. WHO. Field guide for malaria epidemic assessment and reporting. Geneva: World Health Organization; 2004. http://apps.who.int/iris/bitstream/10665/68764/1/WHO_HTM_MAL_2004.1097.pdf. Accessed 25 Oct 2015

10. Kelly G, Tanner M, Vallely A, Clements A. Malaria elimination: moving forward with spatial decision support systems. Trends Parasitol. 2012;28:297-304.

11. Thomson M, Connor S. The development of malaria early warning systems for Africa. Trends Parasitol. 2001;17:438-45. doi:10.1016/ S1471-4922(01)02077-3.

12. Hay S, Were E, Renshaw M, Noor A, Ochola S, Olusanmi L, et al. Forecasting, warning, and detection of malaria epidemics: a case study. Lancet. 2003;361:1705-6.

13. LiT, Yang Zh, Wang M. Temperature, relative humidity and sunshine may be the effective predictors for occurrence of malaria in Guangzhou, southern China, 2006-2012. Parasit Vectors. 2013;6:155. doi:10.1186/1756-3305-6-155.

14. Zhao X, Chen F, Feng Z, Li X, Zhou X. The temporal lagged association between meteorological factors and malaria in 30 counties in south-west China: a multilevel distributed lag non-linear analysis. Malar J. 2014;13:57. doi:10.1186/1475-2875-13-57. 
15. Nkurunziza H. Albrecht Gebhardt A, Pil J. Geo-additive modelling of malaria in Burundi. Malar J. 2011;10:234.

16. Loha E, Lindtjørn B. Model variations in predicting incidence of Plasmodium falciparum malaria using 1998-2007 morbidity and meteorological data from south Ethiopia. Malar J. 2010;9:166.

17. Mateus J, Carrasquilla G. Predictors of local malaria outbreaks: an approach to the development of an early warning system in Colombia. Mem Inst Oswaldo Cruz. 2011;106(Suppl 1):107-13

18. Sainz-Elipe S, Manuel Latorre J, Escosa R, Masià M, Vicent Fuentes M, Mas-Coma S, et al. Malaria resurgence risk in southern Europe: climate assessment in an historically endemic area of rice fields at the Mediterranean shore of Spain. Malar J. 2010;9:221.

19. Zeynalzadeh R, Borzouian S, Ghajari AR. Determine of the Status of Provinces in case of Human Development Indicators in Education, 1997-2009 in period] [In Persian. Q J Hum Geogr. 2012;4:63.

20. Statistical Center of Iran. [National portal of statistics][In Persian], Available from: http://www.sci.org.ir/sites/yearbook/year_book_doc/88-11-08.pdf. Accessed 25 Oct 2015.

21. Statistical Center of Sistan and Baluchestan province portal [In Persian]. http://www.sbportal.ir/sbportalsd_content/media/ image/2014/05/2662_orig.pdf. Accessed 25 Oct 2015.

22. WHO. World malaria report 2012. Geneva: World Health Organization; 2012. http://www.who.int/malaria/publications/world_malaria_ report_2012/wmr2012 full_report.pdf. Accessed 31 Dec 2012.

23. WHO. Terminology of malaria and of malaria eradication: report of a drafting committee. Geneva: World Health Organization; 1963.

24. Kousalya P, Reddy G, Supraja S, Prasad V. Analytical hierarchy process approach- an application of engineering education. Mathematica Aeterna. 2012;10:861.

25. Liberatore $M$, Nydick $R$. The analytic hierarchy process in medical and health care decision making: a literature review. Eur J Oper Res. 2008;189:194-207. doi:10.1016/j.ejor.2007.05.001.
26. Barnett D, Balicer R, Blodgett D, Fews A, Parker C, Links J. The application of the haddon matrix to public health readiness and response planning. Environ Health Perspect. 2005;113:561-6. doi:10.1289/ehp.7491.

27. Ostovar A, Raeisi A, Haghdoost A, Ranjbar M, Rahimi A, Sheikhzadeh K. Lessons learnt from malaria epidemics in the Islamic Republic of Iran. East Mediterr Health J. 2012;18:864.

28. Grover-Kopec E, Kawano M, Klaver R, Blumenthal B, Ceccato P, Connor S. An online operational rainfall-monitoring resource for epidemic malaria early warning systems in Africa. Malar J. 2005;4:6.

29. Kumar D, Andimuthu R, Rajan R, Venkatesan M. Spatial trend, environmental and socioeconomic factors associated with malaria prevalence in Chennai. Malar J. 2014;13:14.

30. Haghdoost A, Alexander N, Cox J. Modelling of malaria temporal variations in Iran. Trop Med IntHealth. 2008;13:1501-8.

31. Chatterjee C, Sarkar R. Multi-step polynomial regression method to model and forecast malaria incidence. PLoS One. 2009;4:e4726.

32. Adimi F, Soebiyanto R, Safi N, Kiang R. Towards malaria risk prediction in Afghanistan using remote sensing. Malar J. 2010;9:125.

33. Wangdi K, Singhasivanon P, Silawan T, Lawpoolsri S, White N, Kaewkungwal J. Development of temporal modelling for forecasting and prediction of malaria infections using time-series and ARIMAX analyses: a case study in endemic districts of Bhutan. Malar J. 2010;9:251.

34. Zacarias $\mathrm{O}$, Andersson M. Spatial and temporal patterns of malaria incidence in Mozambique. Malar J. 2011;10:189.

35. Ranjbar M, Gorgij Kh, Mohammadi M, Haghdoost A, Ansarimoghadam A, Nikpour F, et al. Efficacy of applying self-assessment of larviciding operation, Chabahar, Iran. Malar J. 2012;11:329.

\section{Submit your next manuscript to BioMed Central and we will help you at every step:}

- We accept pre-submission inquiries

- Our selector tool helps you to find the most relevant journal

- We provide round the clock customer support

- Convenient online submission

- Thorough peer review

- Inclusion in PubMed and all major indexing services

- Maximum visibility for your research

Submit your manuscript at www.biomedcentral.com/submit

\section{(O) Biomed Central}

